\title{
POESIE/POETRY
}

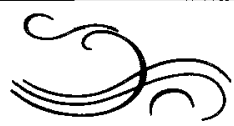

\section{La Vieille}

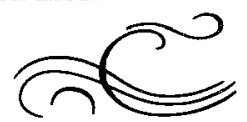

Elle s'arrêta devant la confiserie; on est bien ici ce soir, pensa-t-elle, dans cette ruelle où le vacarme des grands boulevards s'affaisse enfin et le silence commence à se disputer avec les réverbérations infernales de la capitale. Oui, en effet, on est bien ici ce soir, pensa-t-elle.

Elle laissa tomber les sacs en plastique, les porte-tout de sa vie matérielle, et d'un mouvement vif, pareil à celui d'un chat qui se lèche soudain, elle se gratta la cheville à travers le trou d'un bas qui, depuis longtemps, ne tenait plus.

Se penchant ainsi, elle vit du coin de l'œil, dans la vitrine, des boîtes de calissons d'Aix rangées en pyramide, une pâte d'amande, pensa-t-elle, faite pour réchauffer des jours de mistral et de misère.

Puis son regard tomba sur des chocolats de toute provenance. Les uns, venus de Venise, faisaient appel aux délices d'un palais de vieux doge; d'autres, nés comme Charlemagne au pays de la Meuse, hochaient fièrement leur tête de bronze; d'autres encore, cuirassés de rouge, de vert, d'argent et d'or, se présentaient en défilé comme des chevaliers d'autrefois.

Elle ne pouvait pas en croire ses yeux. De l'autre côté du panneau de verre un spectacle fantastique se déroulait. Là, tout s'animait, tout se remuait comme dans un conte de fées. Devant elle, pour elle, à portée de bras, les nougats formèrent un cercle, se mirent à danser; les pralines chantaient la Carmagnole; les fruits confits abandonnèrent leur panier et s'approchèrent de la vitre; des pastilles couraient partout. Tous appelaient son nom en souriant. Tous lui faisaient signe...

LittéRéalité, Vol. II, No. 1, Printemps/Spring 1990 
Le lendemain, à l'heure de l'ouverture, devant la vitre cassée, le propriétaire parlait doucement avec l'agent qui écrivait dans un carnet.

-C'est tout ce qu'elle a pris, la vieille?

-Oui, c'est tout, un cornet de dragées.

Freeman G. Henry

(University of South Carolina, Columbia)

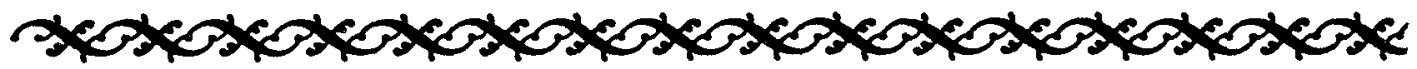

